Innovative Applications of O.R.

\title{
Management of agricultural research centers in Brazil: A DEA application using a dynamic GMM approach
}

\author{
Geraldo da Silva e Souza, Eliane Gonçalves Gomes* \\ Brazilian Agricultural Research Corporation (Embrapa), Parque Estação Biológica, Av. W3 Norte Final, Asa Norte, 70770-901 Brasília, DF, Brazil
}

\section{A R T I C L E I N F O}

Article history:

Received 25 February 2014

Accepted 21 July 2014

Available online 29 July 2014

\section{Keywords:}

Data envelopment analysis

Contextual variables

Panel data

Fractional regression

GMM

\begin{abstract}
A B S T R A C T
In this paper, we measure the performance for each of the Brazilian Agricultural Research Corporation research centers by means of a Data Envelopment Analysis model. Performance data are available for a panel covering the period 2002-2009. The approach is instrumentalist, in the sense of Ramalho, Ramalho, and Henriques (2010). We investigate the effects on performance of contextual variable indicators related to the intensity of partnerships and revenue generation. For this purpose, we propose a fractional nonlinear regression model and dynamic GMM (Generalized Method of Moments) estimation. We do not rule out the endogeneity of the contextual variables, cross-sectional correlation or autocorrelation within the panel. We conclude that revenue generation and previous performance scores are statistically significant and positively associated with actual performance.
\end{abstract}

(ㄷ) 2014 Elsevier B.V. All rights reserved.

\section{Introduction}

Using a Data Envelopment Analysis (DEA) performance model with a single output and a three-dimensional input vector, the Brazilian Agricultural Research Corporation (Embrapa) has monitored the production processes of 37 of its 42 research centers since 1996. Souza, Gomes, and Staub (2010), Souza, Souza, and Gomes (2011) have studied the effect of contextual variables on this performance measurement. In Souza, Gomes, and Staub (2010) the response measure is not DEA, but it is measured in terms of the ratio of the conditional to the non-conditional FDH (Free Disposal Hull) as proposed by Daraio and Simar (2007). The contextual variables analyzed were revenue generation, processes improvements, intensity of partnerships, type and size of a research center, and management changes for the period 1999-2006. Only revenue generation and lagged values of the response were found to be statistically significant. In the study by Souza, Souza, and Gomes (2011), only deterministic effects such as time, type and size were investigated for the period 2002-2008. The dependent variable in this case was the variable returns to scale DEA score (DEA-BCC) and only time was statistically significant. The statistical models used in both articles were defined by dynamic panels such as in Arellano and Bond (1991), Arellano and Bover (1995) and Blundell and Bond (1998). The main technical drawbacks of this approach are that the models used in Souza et al. $(2010,2011)$ do not take into

\footnotetext{
* Corresponding author. Tel.: +55 61 34484476; fax: +55 6134484884 .

E-mail addresses: geraldo.souza@embrapa.br (G. da Silva e Souza), eliane. gomes@embrapa.br (E.G. Gomes).
}

account potential heteroskedasticity, cross-sectional correlations between the Decision-Making Units (DMUs) and, in the case of the FDH ratio response, potential endogeneity of the contextual variables. Daraio and Simar (2007) do not provide a proper statistical test for the latter. Another drawback of these previous studies is the specification of the production model. Many output indicators were aggregated into a single output measure and some of the contextual variables (processes improvements and impact of technologies) were not measured on a proper ratio scale and reflected only a subjective non-categorized value of judgment.

This article is also concerned with the identification of contextual variables, whether these are external to the production process or not, which may affect or contribute to efficiency. These variables are typically found in the control of the institution. The assessment of their effect is an issue of managerial importance, since they may serve as a tuning device to improve management practices, leading to units that are more efficient. Here, we are interested in studying the effects of indicators related to the intensity of partnerships and revenue generation on a DEA technical efficiency score; based on past studies these are two key variables for management. Recently it has been argued within Embrapa that competition induced by the performance model may be negatively associated with the establishment of fruitful internal partnerships.

Contrary to Souza et al. (2010, 2011), our approach to performance here is based on multiple outputs. Attention is given to the use of robust econometric statistical models.

It is important to realize that the statistical identification of factors that influence DEA performance measures demands appropriate statistical modeling. The literature offers a number of 
parametric and semi-parametric statistical models for assessing the significance of covariates in DEA models; detailed discussions can be seen in, for instance, Hoff (2007), Simar and Wilson (2007, 2011), Gomes, Souza, and Vivaldi (2008), Banker and Natarajan (2008), Banker and Natarajan (2011), McDonald (2009), Ramalho et al. (2010), Ramalho, Ramalho, and Murteira (2011), Bădin, Daraio, and Simar (2012), and Johnson and Kuosmanen (2012). These articles typically propose alternative methods of analysis as fractional regressions, and discuss the use of statistical techniques such as ordinary least squares, Tobit models, analysis of variance, maximum likelihood, quasi-maximum likelihood and bootstrapping. The approach followed in most cases is based on a two-stage DEA or conditional FDH. Efficiency (performance) measurements are computed in the first stage and are then regressed on a set of covariates in the second stage.

Two main problems arise in the two-stage approach: (a) the correlation between efficiency measurements in the first stage and (b) the endogeneity of the contextual variables, which may be involved in production decisions. The first problem, given that the contextual variables are indeed exogenous, does not seem to invalidate the approach, even in the presence of heteroskedasticity (e.g. Ramalho, Ramalho, \& Murteira, 2011; Ramalho et al., 2010). There are cases in which the correlation is not a problem at all. For example, in an analysis of variance model with a single positive response, the standard statistical analysis for treatment comparisons is obtained by considering a simple DEA model with a unit input. In this instance, the division of a response observation by its maximum induces the correlation. $F$-tests and $t$-tests are invariant under location and scale transformations (for additional details, see Gomes et al., 2008). Ramalho et al. (2010, 2011) also do not see any apparent problems with this assumption.

If the contextual variables are endogenous, as Simar and Wilson (2007) point out, we believe that the condition may invalidate the statistical analysis in a way similar to what happens in simultaneous equation models. In this case, it is appealing to consider instrumental variable estimation in the second stage. In order to lessen the covariates' effects causing interference on the production frontier, Daraio and Simar (2007) and Bădin et al. (2012) propose the use of performance measures based on the conditional FDH in order to obtain insights into the effects of covariates. However, the correlation problem, as well as a formal test for the validity of the model, is not addressed by the authors.

The approach we propose here considers a panel data structure assuming a bounded nonlinear response function. The expected efficiency value is defined by a real valued monotonic function with values in $[0,1]$, dependent on a linear construct defined by the set of covariates. Performance scores are viewed in the context of the instrumentalist approach described by Ramalho et al. (2010): DEA scores are treated as descriptive measures of the relative technical efficiency of the DMUs (Decision-Making Units) under analysis. This means that in a two-stage approach, DEA scores computed in the first stage can be treated as any other dependent variable in regression analysis. Therefore, as Ramalho et al. (2010, pp. 240) point out, "parameter estimation and inference in the second stage may be carried out using standard procedures." We assume the data follow a model in which the contextual variables may be endogenous. Endogeneity is accounted for through proper panel instrumentalization. Additionally, cross-sectional correlation and autocorrelation are also considered in the estimation process. To the best of our knowledge, this order of ideas represents a new contribution to the two-stage DEA/FDH literature.

It is important to emphasize that the earlier panel data analysis in the same context considered herein and appearing in Souza et al. (2010, 2011) differ in the following key aspects:
1. The contextual variables in the articles are not the same. We now consider only two covariates of management interest that may be endogenous to the production process. The Souza et al. (2011) article considers only purely exogenous variables as factor effects (time and type dummies) and in Souza et al. (2010) another set of covariates are considered, completely disregarding endogeneity. The analysis in Souza et al. (2010) is based on the conditional and unconditional FDH, following Daraio and Simar (2007).

2. In both articles, a first order autoregressive process $(\operatorname{AR}(1))$ is imposed for the DEA/FDH measurements - the dependent observations - and fits the dynamic panel model proposed by Blundell and Bond (1998). Although this model is robust against second order autocorrelation, it does not take into account the correlation between the DMUs induced by DEA computations nor the potential endogeneity of the contextual variables. Here we propose a different GMM (Generalized Method of Moments) approach, which is robust against endogeneity, cross-sectional and serial correlation, and heteroskedasticity.

3. No explicit assumption is made regarding the expected value of the DEA measurements in the 2010 and 2011 papers other than the AR(1) evolution of the response. In order to better addressing this problem, we now propose combining the methods of fractional regression with GMM to produce a more adequate model to describe the response.

Our contribution is concerned with resolving the four main problems related to applied works involving DEA/FDH responses in two-stage regressions, which are recurrent in the modern literature on the subject, namely correlations between DMUs, endogeneity of contextual variables, cross-sectional and serial correlation, heteroskedasticity, and proper functional modeling of the response. Additionally, it is possible to assess the model goodness of fit.

Our discussion proceeds as follows. In Section 2, we review Embrapa's performance process and the production variables used in the analysis, including the contextual variables. In Section 3, we discuss the estimation process that we recommend for panel data, overcoming the statistical problems above described. In Section 4, we present the statistical results. Finally, Section 5 summarizes our findings.

\section{Embrapa's performance model}

Embrapa's research system currently comprises 42 research centers, or DMUs. Five of these units were recently created (2010-2012) and are not included in the evaluation system discussed here; hence, our sample consists of 37 DMUs. The input and output variables were defined from a set of performance indicators known to the company since 1991. Embrapa routinely uses these indicators to monitor performance on an annual basis. With the active participation of the board of directors of Embrapa as well as the administration of each of its research units, 28 output and three input indicators were identified as being representative of production actions in the company. In this paper, the performance measure computed within years is a technical efficiency DEA score based on three outputs and three inputs indices. We are concerned with detecting the factors of managerial importance that may influence the performance measurements (negatively or positively). Further details on the performance evaluation system carried out by Embrapa can be seen in Souza et al. $(2010,2011)$ and Souza and Gomes (2013).

On the one hand, any sensible DEA analysis cannot be performed with a large set of output/input variables. On the other hand, too much aggregation may be subject to criticism. In the present case, to avoid the determination of a weighting system 
to combine outputs measured in different scales, we performed a prior robust multivariate analysis on the output data transformed to ranks, arriving at three dimensions representative of the company's research and development (R\&D) efforts. This analysis was carried out using multivariate normal factor analysis. In each dimension the number of factors were determined by a maximum likelihood method (Mardia, Kent, \& Bibby, 1979) and the relative importance of each variable was determined by its relative variance (relative communality). The final variables chosen are scientific publications (number of articles published in indexed journals), technical publications (number of technical reports) and transfer of technology (number of field days). The corresponding vector defines the three-dimensional output.

The input side of Embrapa's performance process is composed of three factors: personnel costs (salaries plus labor duties), operational costs (expenses resulting from the consumption of materials, travel and services, less income from production projects) and capital (measured by depreciation).

The final set of production variables is therefore defined by a three-dimensional output vector $\left(y^{1}, y^{2}, y^{3}\right)$ and a three-dimensional input vector $\left(x^{1}, x^{2}, x^{3}\right)$ observed for the period 2002-2009. We have balanced information on the vector $\left(x^{1}, x^{2}, x^{3}, y^{1}, y^{2}, y^{3}\right)$ for Embrapa's 37 research centers. All production variables are rank transformed within years prior to the analysis. Following the terminology of Ramalho et al. (2010), we see the DEA efficiency measures the context of an instrumentalist approach rather than resulting from a true production process, from which the research centers represent a sample.

Measures of efficiency are calculated and used to ensure progress toward several managerial objectives. One of the most important is the negotiation of performance goals with the individual research units. The proper management of the evaluation system as a whole requires the identification of best practices and implementation of actions with a view to the improvement in overall performance and reduction in the variability in efficiency between research units. Parallel to this endeavor is the identification of non-production variables that may affect (positively or negatively) the system. It is of managerial interest to detect the controllable attributes that cause or contribute to the observed best practices.

We used the information for the period 2002-2009 to analyze the effects of the contextual variables on Embrapa's performance. In this context, we considered two continuous covariates, which are indicators that correspond to the intensity of partnerships (PARC) and revenue generation (REC). They are also rank transformed within years. Other variables considered in a previous analysis were impact of technologies and processes improvements, but these variables were measured in a scale too subjective to be useful in our discussion: the technologies were chosen by the DMUs and the processes improvements were evaluated by means of perceptions of referees not randomly chosen. Exclusion of these variables does not lead to biases in the analysis.

REC is a ratio of external to government funding. Each research unit negotiates with the board of directors an amount of external funds it expects to raise each year. The attainment of this goal is checked at the end of the evaluation period (a year) by the corporation's finance department. The measurement takes into account both direct and indirect funds. Direct funds are funds received from sales, contracts and credit from other public institutions, which are not part of Embrapa's budget. Indirect funds are those received from the private sector and other partners. REC is the ratio between the sum of direct and indirect revenues raised by each research center and the amount of funds received from the national treasury. Managers expect that, over time, this indicator will show an upward trend, indicating a reduced dependence on resources from the national treasury on the part of Embrapa's research centers.
PARC is a weighted index of the research or technology knowledge transfer actions (partnerships) scheduled by each research center and performed during the assessment year; the administration defines the weights. Partnerships in a research program are entered via projects (weight $=0.35$ ), scientific publications (weight $=0.15$ ), technical publications (weight $=0.15$ ), the development of technologies, products and services ( weight $=0.15$ ), the attainment of final results (weight $=0.15$ ), and technology transfer and image promotion (weight $=0.20$ ). External and internal partnerships are equally weighted. The score of partnerships is normalized by the number of researchers in each center. By the very nature of its construction, it is expected some association of PARC with the production process. PARC counts number of partnerships in each of its components, not the amount of output. The question raised within the company is whether the association with efficiency is negative. To deal properly with the subject, we considered the variable PARC endogenous to the production process, as well as REC.

Our use of ranks has two purposes. First, it roughly corresponds to a common usage in nonparametric statistical analysis where typically they allow analysis of multidimensional data using multivariate normal methods (Conover, 1999). Secondly, ranks are robust to the presence of outlying observations in the production space making the DMUs more comparable. In our application, despite the reduction of scale of operation induced by the rank transformation, we still notice scale problems since DEA-BCC and the constant returns to scale DEA (DEA-CCR) measurements differ considerably within years. In this context, we opted for the more benevolent approach defined by the DEA-BCC scores.

\section{Statistical model}

Statistical inference derived from two-stage analysis in the context of DEA is hard to handle. As we have already pointed out, covariates are typically endogenous and therefore they may invalidate standard statistical procedures, such as maximum likelihood and least squares, because of the correlation of the independent variables with the error term. In addition, the DEA computations induce correlations between the DMUs under evaluation. Further, it is necessary to model the DEA response properly, since the observations fall in the interval $[0,1]$.

Ramalho et al. (2010) propose several approaches to deal with two-stage regressions when a DEA response is the dependent variable. The simplest formulation they consider, which avoids the problems associated with linear and Tobit models-see Simar and Wilson $(2007,2011)$ and Ramalho et al. (2010)-is the FRM (Fractional Regression Model) used by Papke and Wooldridge (1996). The only assumption required by the FRM is the correct specification of the conditional mean of the dependent variable (DEA score). In other words, it is assumed that the responses satisfy the moment condition $E\left(\phi_{j}^{*}\right)=F\left(\mu_{j}\right), \mu_{j}=l_{j}^{\prime} \beta$, where $\phi_{j}^{*}$ is the DEA score for the DMU $j, l_{j}$ is the vector of observations on the contextual variables for DMU $j, \beta$ is a vector of unknown parameters and $F$ is some nonlinear function satisfying $0 \leqslant F(\mu) \leqslant 1$. Typical choices for $F$ are the distribution functions of the logistic$F(\mu)=\exp (\mu) /(1+\exp (\mu))$, standard normal $-F(\mu)=\Phi(\mu)$, where $\Phi(\mu)=(1 / \sqrt{2 \pi}) \int_{-\infty}^{\mu} \exp \left(-x^{2} / 2\right) d x$ is the standard normal distribution function, and the inverse extreme value distributions$F(\mu)=1-\exp (-\exp (\mu))$. The idea is to estimate the model by using quasi-maximum likelihood methods, maximum likelihood or nonlinear least squares.

Two points are overlooked in this process: endogeneity and the dependence of the DMUs' scores. None of the proposals by Ramalho et al. (2010) cover these conditions simultaneously. Simar and Wilson (2007) impose strong assumptions (separability) on the production process to avoid endogeneity, while Banker and 

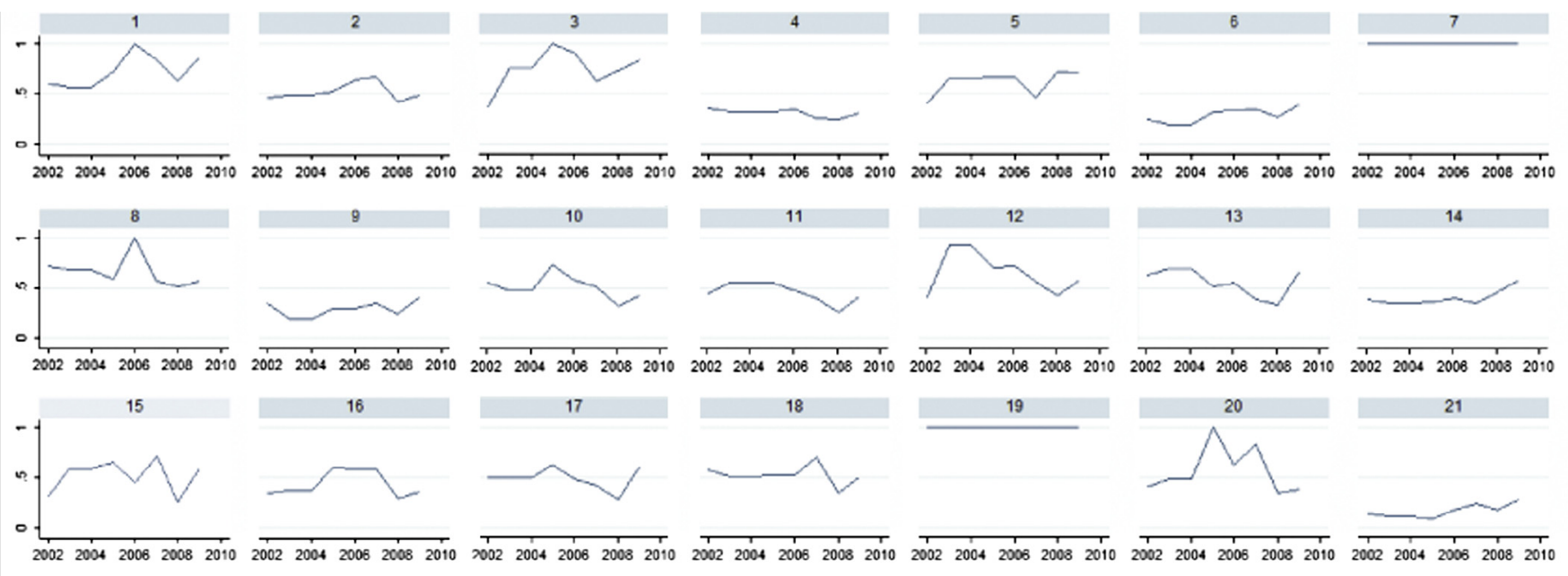

21
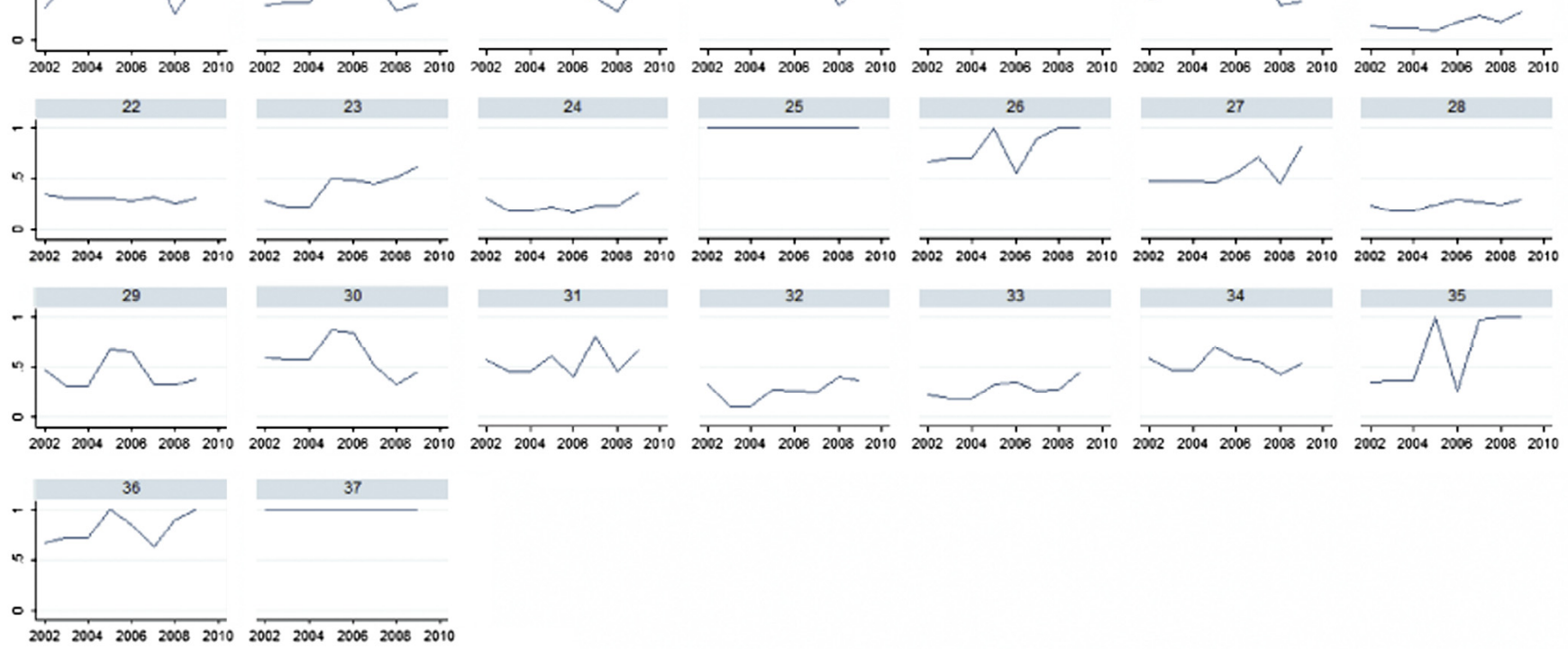

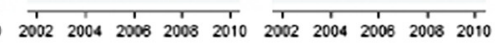
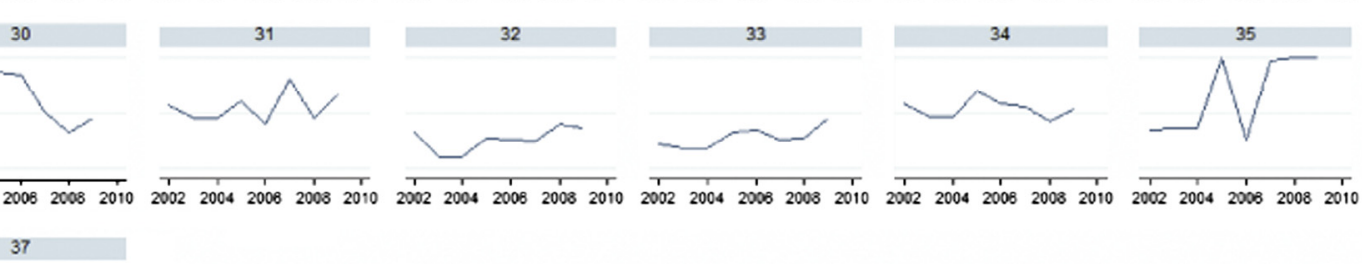

Fig. 1. Evolution of EFFIC (performance scores) by year and DMU. The axes scales are 2002-2010 (horizontal axis) and 0-1(vertical axis) for all plots.

Natarajan (2008) assume the exogeneity of the covariates. The best approach to overcome the problem of endogeneity seems to be the conditional FDH of Daraio and Simar (2007) and Bădin et al. (2012). The latter, however, do not address the correlation induced by the FDH measures in a way similar to what happens with DEA. Our proposal is to combine the moment condition of the FRM with GMM (Generalized Method of Moments) when instruments are available for estimation. Because the GMM allows a test of model specification, including validity of the instruments, it simultaneously takes into account endogeneity, correlation between units and time series errors. It is thus ideal for the instrumentalist approach. For information on the GMM estimation as presented here, see Gallant (1987), Davidson and MacKinnon (1993), Greene (2011) and StataCorp (2012).

We have panel data in which the expected value of a DEA performance response has been modeled as a nonlinear function of the contextual variables. First, the DEA performance measures may be contemporaneously correlated and might show heteroskedasticity. Second, for each DMU, the performance measures may also be correlated over time. Finally, the contextual variables may be endogenous. In such a context, we postulate that efficiencies $\phi_{j}^{*}$ satisfy the FRM $\phi_{j t}^{*}=F\left(l_{j t}^{\prime} \beta\right)+\varepsilon_{j t}$, where $l_{j t}$ is an observation of a vector of the independent covariates that may include strictly exogenous variables, endogenous independent variables, lagged endogenous variables, and time. The subscript $t$ stands for time and $j$ for a panel member, or DMU. The panel is balanced in our application but this does not need to be the case in general. The vector of constants $\beta$, which is the same for all panels in our application, defines the parameters to be estimated. In our case, we have $\mu_{j t}=l_{j t}^{\prime} \beta=\beta_{0}+\beta_{1} R P A R C_{j t}+\beta_{2} R R E C_{j t}+\beta_{3} R_{E F F I C} C_{j t-1}+\beta_{4} t$. Here RPARC, RREC, and REFFIC denote ranks of PARC, REC and EFFIC (DEA efficiency measures), respectively. The components $\varepsilon_{j t}$ are stochastic errors with mean zero. They may be contemporaneously correlated, serially correlated and heteroskedastic. We use panelstyle instruments. For each point in time, we use a different set of instruments, defined by the lagged values of the variables appearing in the model plus the fixed effects. Two lags are used to guarantee no dynamical correlation with the residuals. Indeed, the matrix of instruments used here is of the following form:

$$
Z=\left(\begin{array}{cccc}
z_{1} & 0 & \ldots & 0 \\
0 & z_{2} & \ldots & 0 \\
\vdots & \vdots & \ddots & \vdots \\
0 & 0 & \ldots & z_{T}
\end{array}\right)
$$

where $Z$ is a block diagonal matrix and $z_{t}$ is the matrix of instruments for period $t$, of dimension 37 by 8 , including first and second order lags of the contextual $\left(l^{1}, l^{2}\right)$ variables and first and second order lags of the dependent variable $\left(l^{3}\right)$, time effect $(t)$, and a column of ones. Notice that the $j$ th row of $z_{t}$ is therefore $z_{j t}=\left(l_{j t-1}^{1}, l_{j t-2}^{1}, l_{j t-1}^{2}, l_{j t-2}^{2}, l_{j t-1}^{3}, l_{j t-2}^{3}, t, 1\right)$. 


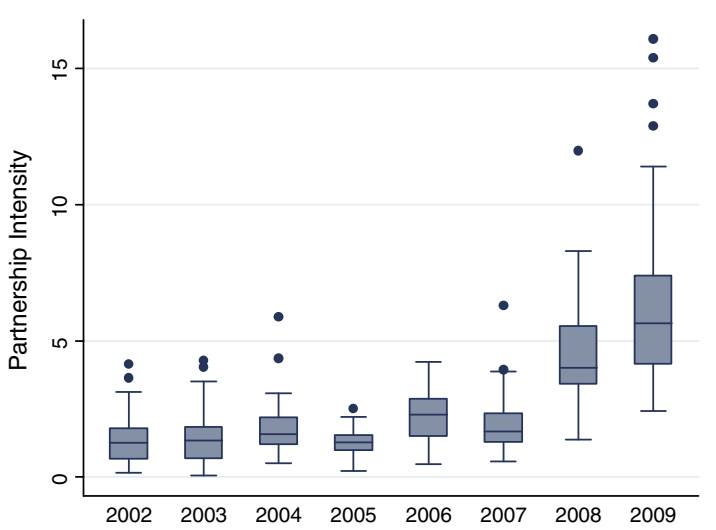

Fig. 2. Distribution of PARC (partnership intensity) by year.

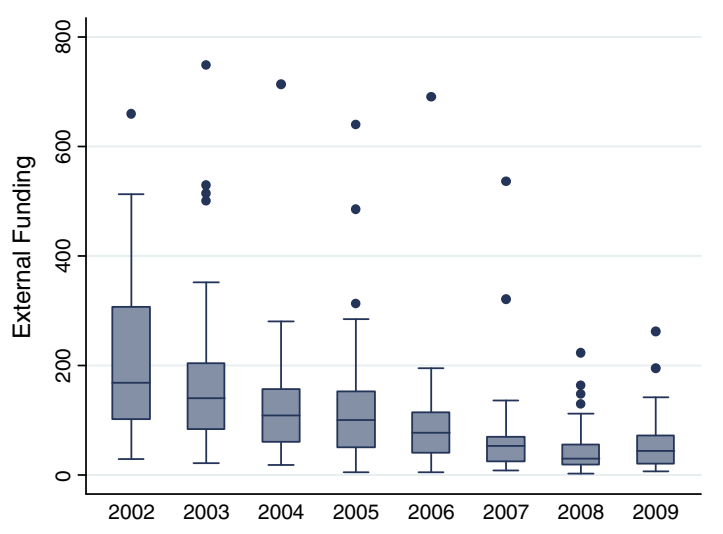

Fig. 3. Distribution of REC (external funding) by year.

Let $\varepsilon_{t}=q\left(\phi_{t}^{*}, l_{t}, \beta\right)$, where, for each $t, \varepsilon_{t}$ is a vector of dimension 37 with the typical element $\varepsilon_{j t}$. The function $q$ has dimension 37 with the typical element $\phi_{j t}^{*}-F\left(l_{j t}^{\prime} \beta\right)$. We assume $E\left(\varepsilon_{t}\right)=0, E\left(\varepsilon_{t} \varepsilon_{t}^{\prime}\right)=\Sigma$. Moreover, $E\left(\varepsilon_{t} \otimes \operatorname{vec}\left(z_{t}\right)\right)=0$, where $\otimes$ denotes the direct product of matrices and $v e c($.$) is the vectorization, i.e.,$ converts a matrix $A=\left(a_{i j}\right)$ into a column vector $m n \times 1$ obtained by stacking the columns of the matrix $A$ on top of one another.

The moment conditions are defined by

$E\left(\frac{1}{6} \sum_{t=3}^{8} m\left(\phi_{t}^{*}, l_{t}^{\prime}, \beta\right)\right)=0, m\left(\phi_{t}^{*}, l_{t}^{\prime}, \beta\right)=q\left(\phi_{t}^{*}, l_{t}^{\prime}, \beta\right) \otimes \operatorname{vec}\left(z_{t}\right)$.

In the GMM estimation, one looks for the vector $\beta$ minimizing

$S(\beta, V)=\left[\sum_{t=3}^{8} m\left(\phi_{t}^{*}, l_{t}^{\prime}, \beta\right)\right]^{\prime} V^{-1}\left[\sum_{t=3}^{8} m\left(\phi_{t}^{*}, l_{t}^{\prime}, \beta\right)\right]$

where $V$ is a positive definite weight matrix. By convenient choice of $V=\widehat{V}$, the estimation method can be chosen to provide standard errors robust against contemporaneous and serial correlation. See Gallant (1987).

Finally, Hansen's (1982) $J$ test of over-identifying restrictions (goodness of fit and validity of instruments) is given by $37 \times S(\beta, \widehat{V})$, which is chi-square with 32 degrees of freedom for our application.

\section{Statistical results}

Fig. 1 shows the performance evolution by DMU over time. Units $1,7,8,12,26,27,35$ and 36 are fully efficient during the analyzed period. The distribution of each of the contextual variables by
Table 1

The GMM nonlinear regression of DEA performance (EFFIC) on the contextual variables RPARC, RREC, Lagged REFFIC and trend. The response is defined by the logistic distribution and the standard errors take into account cross-sectional and serial correlations.

\begin{tabular}{lrlrrrr}
\hline & Coefficient & $\begin{array}{l}\text { HAC standard } \\
\text { error }\end{array}$ & & $P>|z|$ & $\begin{array}{l}\text { [95\% Confidence } \\
\text { interval] }\end{array}$ \\
\hline Constant & 130.6655 & 36.3426 & 3.60 & 0.000 & 59.4354 & 201.8957 \\
RPARC & -0.0058 & 0.0041 & -1.41 & 0.160 & -0.0139 & 0.0023 \\
RREC & 0.0190 & 0.0073 & 2.62 & 0.009 & 0.0048 & 0.0332 \\
Lag (REFFIC) & 0.1075 & 0.0070 & 15.38 & 0.000 & 0.0938 & 0.1212 \\
Trend & -0.0650 & 0.0181 & -3.59 & 0.000 & -0.1005 & -0.0295 \\
\hline
\end{tabular}

year is shown in Figs. 2 and 3. The upward trend in partnerships is clear, reflecting the concerns of Embrapa's administration regarding potential competition between research centers.

The units' efforts to obtain external funding are depicted in Fig. 3 and show a downward trend over time. This should be a point of concern for the company's administration and it may be one of the reasons for the absence of an overall upward trend in efficiency.

Our statistical analysis begins by defining the exogenous variables and instruments to be used in the GMM analysis. The model considers the within-year rank transformations of the intensity of partnership (RPARC), revenue generation (RREC), as well as lags of ranked DEA efficiency as exogenous variables. The instruments are of the panel data type. For each point in time, we consider an instrument lag of order one and two of all variables, and time, and a column of ones, corresponding to the presence of an independent term in the model. Therefore, there are 8 instruments.

Table 1 shows the final GMM-FRM estimates under cross-sectional and serial correlations for the logistic response. Three models were considered: logistic, normal and inverse extreme value. The corresponding minimum chi-square values are 31.516 , 31.591 and 31.932. The logistic is the best model, followed by the normal and the inverse extreme value. The $J$ test statistic for over-identifying restrictions is 31.516 ( $p$-value 0.491 ) and does not invalidate the model specification or the instruments.

REC and past ranked efficiency scores exert positive effects on performance. PARC is not significant. This is an important result for management. A criticism of the performance evaluation model used here is that it may cause unwanted competition between research units; however, this is not the case. The effort to generate external funding does translate into increased performance. The message here, however, is that the company may not be effectively enforcing its policy on external funding (see the downward trend in Fig. 3), negatively affecting efficiency. This may be the reason for the negative trend effect.

\section{Summary and conclusions}

We fit a panel data model for performance data generated by Embrapa's research centers during the period 2002-2009. The measure of performance is DEA under the assumption of variable returns to scale. The panel data model postulates that performance is a nonlinear function of the contextual variables 'intensity of partnerships', 'external revenue generation', 'trend' and 'past DEA performance'. The GMM estimation was used as a way to overcome the endogeneity of the covariates, heteroskedasticity, crosssectional correlations and serial correlations of the DMUs.

We found statistically significant effects for all contextual variables, with the exception of 'intensity of partnerships.' The other statistically significant covariates show positive associations.

We conclude that funding from external sources, other than the government, is decreasing over time, but remains a key factor to increasing performance. The decrease in performance over time 
may be the reason for the presence of a strong negative trend in performance over time. The level of partnerships does not seem to significantly decrease performance.

\section{Acknowledgment}

To the National Council for Scientific and Technological Development - Brazil, for financial support.

\section{References}

Arellano, M., \& Bond, S. (1991). Some tests of specification for panel data: Monte Carlo evidence and an application to employment equations. Review of Economic Studies, 58(2), 277-297.

Arellano, M., \& Bover, O. (1995). Another look at the instrumental variable estimation of the error-components models. Journal of Econometrics, 68, 29-51.

Bădin, L., Daraio, C., \& Simar, L. (2012). How to measure the impact of environmental factors in a nonparametric production model. European Journal of Operational Research, 223(3), 818-833.

Banker, R. D., \& Natarajan, R. (2008). Evaluating contextual variables affecting productivity using data envelopment analysis. Operations Research, 56, 48-58.

Banker, R. D. \& Natarajan, R. (2011). Statistical tests based on DEA efficiency scores. In W. W. Cooper, L. M. Seiford, \& J. Zhu (Eds.), Handbook on Data Envelopment Analysis (pp. 273-296). Boston: Kluwer International Series.

Blundell, R., \& Bond, S. (1998). Initial conditions and moment restrictions in dynamic panel data models. Journal of Econometrics, 87, 115-143.

Conover, W. J. (1999). Practical nonparametric statistics (3rd ed.). New Jersey: Wiley.

Daraio, C., \& Simar, L. (2007). Advanced robust and nonparametric methods in efficiency analysis. New York: Springer.

Davidson, R., \& MacKinnon, J. G. (1993). Estimation and inference in econometrics. New York: Oxford University Press.

Gallant, A. R. (1987). Nonlinear statistical models. New York: Wiley.

Gomes, E. G., Souza, G. S., \& Vivaldi, L. J. (2008). Two-stage inference in experimental design using DEA: An application to intercropping and evidence from randomization theory. Pesquisa Operacional, 28, 339-354.
Greene, W. H. (2011). Econometric analysis (7th ed.). New Jersey: Prentice Hall.

Hansen, L. P. (1982). Large sample properties of generalized method of moments estimators. Econometrica, 50(4), 1029-1054.

Hoff, A. (2007). Second stage DEA: Comparison of approaches for modelling the DEA score. European Journal of Operational Research, 181(1), 425-435.

Johnson, A. L., \& Kuosmanen, T. (2012). One-stage and two-stage DEA estimation of the effects of contextual variables. European Journal of Operational Research $220(2), 559-570$

Mardia, K. V., Kent, J. T., \& Bibby, J. M. (1979). Multivariate analysis. San Diego: Academic Press.

McDonald, J. (2009). Using least squares and tobit in second stage DEA efficiency analyses. European Journal of Operational Research, 197(2), 792-798.

Papke, L. E., \& Wooldridge, J. M. (1996). Econometric methods for fractional response variables with an application to $401(\mathrm{k})$ plan participation rates. Journal of Applied Econometrics, 11(6), 619-632.

Ramalho, E. A., Ramalho, J. J. S., \& Henriques, P. D. (2010). Fractional regression models for second stage DEA efficiency analyses. Journal of Productivity Analysis, 34, 239-255.

Ramalho, E. A. Ramalho, J. J. S., \& Murteira, J. M. R. (2011). Alternative estimating and testing empirical strategies for fractional regression models. Journal of Economic Surveys, 25(1), 19-68.

Simar, L., \& Wilson, P. W. (2007). Estimation and inference in two-stage, semiparametric models of production processes. Journal of Econometrics, 136(1), 31-64.

Simar, L., \& Wilson, P. W. (2011). Two-stage DEA: Caveat emptor. Journal of Productivity Analysis, 36, 205-218.

Souza, G. S., \& Gomes, E. G. (2013). Scale of operation, allocative inefficiencies and separability of inputs and outputs in agricultural research. Pesquisa Operacional 33, 399-415.

Souza, G. S., Gomes, E. G., \& Staub, R. B. (2010). Probabilistic measures of efficiency and the influence of contextual variables in nonparametric production models: An application to agricultural research in Brazil. International Transactions in Operational Research, 17, 351-363.

Souza, G. S., Souza, M. O., \& Gomes, E. G. (2011). Computing confidence intervals for output-oriented DEA models: An application to agricultural research in Brazil Journal of the Operational Research Society, 62, 1844-1850.

StataCorp (2012). Longitudinal-data/panel-data reference manual. Stata Press: College Station. 